\title{
Más de una década de la Marcha de la Gorra en Córdoba, Argentina: un análisis diacrónico de sus demandas
}

Macarena Roldán ${ }^{1}$

Recibido: 29/03/2019

Aceptado: 07/05/2019

\section{RESUMEN}

La Marcha de la Gorra es una manifestación anual que se realiza en la ciudad de Córdoba, Argentina, desde el año 2007, para denunciar el abuso y la represión ejercidos por las fuerzas policiales contra los jóvenes de sectores populares. Desde el año 2012 se desarrolla un trabajo etnográfico sobre esta acción colectiva que reúne un conjunto de estrategias de resistencia orientadas a cuestionar modelos represivos y de control en el espacio público. A lo largo de más de una década, las principales demandas de la Marcha han ido modificándose, acompañando diversas transformaciones coyunturales y de la mano de instancias de debate al interior de su mesa organizativa. Considerando el proceso multidimensional y complejo de elaboración política -simbólica y afectiva- de la Marcha, el objetivo de este trabajo es reflexionar sobre la construcción de demandas particulares a partir del análisis cualitativo de las gráficas y consignas oficiales de cada una de sus ediciones. Finalmente, se presenta un conjunto de reflexiones en torno a las aproximaciones interdisciplinarias y multimetodológicas que supone la exploración de acciones colectivas desde la perspectiva de las ciencias sociales.

Palabras clave | Acción colectiva, juventudes, etnografía de evento, Marcha de la Gorra, resistencia

\footnotetext{
${ }^{1}$ Licenciada en Psicología por la Universidad Nacional de Córdoba. Becaria doctoral en Centro de Investigaciones y Estudios sobre Cultura y Sociedad (CONICET/UNC). Docente e investigadora de la Universidad Nacional de Córdoba, Argentina. E-mail: macarena_roldan5@hotmail.com
} 


\section{ABSTRACT}

More than a decade of the 'Marcha de la Gorra' in Córdoba, Argentina: a diachronic analysis of its demands.

The 'Marcha de la Gorra' is an annual demonstration that takes place in the city of Córdoba, Argentina, since 2007, with the aim of denouncing the abuse and repression exercised by the police forces against young people in the sectors popular. From 2012, an ethnographic work has been developed on this collective action that brings together a set of resistance strategies aimed at questioning repressive and control models in public space. Throughout more than a decade of history, the main demands of the March have been modified by accompanying various conjunctural transformations and by the hand of different instances of debate within its Organizational Table. Considering the multidimensional and complex process of political elaboration -symbolic and affective- of each edition of the March, the objective of this work is to reflect on the construction of particular demands from the qualitative analysis of the official graphics and slogans of each one of its editions. Finally, a set of reflections on the interdisciplinary and multimetodological approaches that involves the exploration of collective actions from the perspective of the social sciences is presented.

\section{Keywords | Collective action, youths, Marcha de la Gorra - event ethnography, resistance}

\section{INTRODUCCIÓN}

La Marcha de la Gorra es una manifestación multitudinaria (entre 15.000 y 20.000 participantes por edición), con un gran componente juvenil que, desde el año 2007, tiene lugar un día de noviembre en la ciudad de Córdoba, Argentina. En el año 2017 se completó una década de realización ininterrumpida conquistando así su $11^{\circ}$ edición. El organizador más visible de esta movilización es el Colectivo de Jóvenes por Nuestros Derechos, que convoca a la organización de la Marcha. Este colectivo fue creado por un grupo de jóvenes de diversos territorios, algunos/as provenientes de barrios populares de la ciudad, otros, estudiantes universitarios, activistas, sensibles a las problemáticas de hostigamiento y abuso policial que sufren los jóvenes de la ciudad. A lo largo de los 12 años de historia de la Marcha, la composición del Colectivo ha ido mutando -con la incorporación de nuevos integrantes y la salida de algunos miembros- siendo habitado actualmente por once personas. Junto al Colectivo, una multiplicidad de agrupaciones políticas 
y organizaciones sociales de diversa procedencia política o partidaria se reúnen desde el mes de septiembre para conformar la mesa organizativa de la Marcha de la Gorra.

La demanda inicial de esta protesta se vinculaba con instalar un reclamo contra el antiguo Código de Faltas (Ley 8.431) y las prácticas represivas de las fuerzas policiales que tienen como blanco preferencial a los jóvenes de sectores populares. Dicha ley fue remplazada por el Código de Convivencia Ciudadana (Ley 10.326), el cual se encuentra vigente desde el año 2016. Estas legislaciones regulan el campo de las contravenciones en toda la provincia de Córdoba y, entre las figuras más cuestionadas de estos cuerpos legales, pueden encontrarse el "Merodeo" y la "Conducta sospechosa", que habilitan la detención de personas por el solo hecho de que, a juicio de la autoridad actuante, se presume su potencial inclinación a delinquir. En otras palabras, estas figuras habilitan -en los hechos- la detención y sanción de ciudadanos y ciudadanas de acuerdo con el criterio del personal policial, y atentan contra el derecho a circular (Etchichury, 2007). El repudio a estos artículos se hace evidente en diferentes modalidades al interior de la Marcha, desde cánticos que declaman: "No es merodeo, es paseo", hasta consignas que se estampan en banderas y estandartes aludiendo al derecho a la libre circulación y cuestionando la selectividad arbitraria a partir de la cual algunos transitares se constituyen en paseo y otros en merodeo.

Esta arbitrariedad, insistentemente cuestionada, se materializa en el objetosímbolo gorra -que da nombre a la Marcha- en tanto mostración provocadora por parte de los jóvenes, como un símbolo de la etiqueta social por la cual son identificados como peligrosos y son detenidos (Bonvillani, 2015). Así, esta concentración multitudinaria de jóvenes para marchar un día de noviembre por las calles del centro de la ciudad irrumpe en la escena pública de Córdoba bajo la modalidad de una acción colectiva contenciosa (Tarrow, 1997). La Marcha se caracteriza por un despliegue nutrido de intervenciones artísticas y recursos expresivos diversos, de manera que la corporalidad de los marchantes aparece como materialidad desde la cual se denuncia y se repudia la persecución y el abuso policial, al tiempo que es también un locus de expresividad y celebración de la cultura juvenil y popular (Bonvillani \& Roldán, 2017).

La denominada mesa organizativa de la Marcha de la Gorra es convocada por el Colectivo de Jóvenes cada año y comienza a reunirse en el mes de septiembre en encuentros semanales. La participación fluctúa cada año, pero suele estar habitada por aproximadamente cincuenta jóvenes representantes de los diferentes espacios y organizaciones políticas participantes. Esta Mesa tiene una modalidad 
de trabajo por comisiones, a saber: Comunicación, Artística, Seguridad, Finanzas, Documento y, recientemente, Género. Luego del trabajo en comisiones, los participantes se reúnen en una instancia plenaria en la que se comenta acerca de las discusiones e inquietudes de cada espacio de trabajo, y se someten a decisión de tipo asamblearia las cuestiones fundamentales que deben dirimirse para la realización de la Marcha. Entre los diferentes tópicos que se discuten, interesa detenerse en la elección de la consigna oficial bajo la cual se marchará cada año y, luego, las gráficas con las cuales la Marcha será difundida y convocada. Como se verá a continuación, no se trata de una mera cuestión de estéticas o de marketing político, sino que el conjunto de decisiones sobre estas dos dimensiones remite a un proceso de profundas discusiones y negociaciones de sentido que reflejan el complejo proceso político que supone la construcción de una acción colectiva de este tipo. En este sentido, el objetivo de este trabajo es reflexionar acerca de cómo la Marcha ha enunciado políticamente sus demandas a lo largo de estos años, atendiendo a la elaboración de los dilemas y tensiones asociados a la construcción de esta acción colectiva, partiendo de un análisis reflexivo de los procesos decisorios sobre las gráficas y consignas oficiales de cada una de sus ediciones.

\section{ESTRATEGIA METODOLÓGICA}

Esta investigación se enmarca en un proceso de indagación cualitativo y etnográfico. Bonvillani (2014) propone que la investigación cualitativa parte del supuesto de que la realidad está configurada como un universo simbólico construido a partir de negociaciones intersubjetivas sobre el sentido que los sujetos le otorgan a su experiencia. De este modo, las construcciones simbólicas y los procesos de significación que las personas llevan a cabo con relación al mundo se tornan determinantes.

Desde el año 2012 hasta la actualidad, el equipo de investigación que la autora integra viene realizando una etnografía colectiva de la Marcha de la Gorra apoyándose en la "etnografía de evento" (Borges, 2004) como principal estrategia de exploración. Esta última consiste en una aproximación etnográfica que se desarrolla en un lugar-evento caracterizado por la fugacidad y la desestabilización de las coordenadas espacio-temporales que supone un acontecimiento en movimiento como lo es la Marcha. Del mismo modo, el equipo de investigación también lleva adelante una tarea etnográfica con respecto a la mesa organizativa que antecede a cada edición de la Marcha, apoyándose en el registro etnográfico, 
la observación participante (Guber, 2004) y el análisis de documentos como principales herramientas metodológicas. En el caso de la observación participante, esta se lleva a cabo a partir de la incorporación de la investigadora en una de las comisiones de trabajo de la mesa organizativa, desde el año 2014 hasta la última edición. Cabe recordar que las tareas de investigación y registro que se desarrollan en estos espacios son de conocimiento de todos los miembros de la comisión y de la mesa organizativa en general. Esta presencia, doblemente implicada -en el equipo de investigación y como miembro activa de una comisión organizativa-, es siempre refrescada en cada instancia de presentación de los participantes, reunión tras reunión.

En la línea de trabajo de la que parte este artículo, las gráficas oficiales de cada edición de la Marcha son los documentos que constituyen el soporte del análisis, a partir de los cuales se procura visibilizar las discusiones y situaciones contextuales que acompañaron tales producciones. La construcción y el análisis de los datos a partir de imágenes se apoyan, en buena medida, en los aportes de la antropología visual (Belting, 2007) en tanto herramienta que posibilita la descripción y la exploración de las construcciones de sentido sobre la realidad, a partir de la producción y la interpretación de imágenes, y que opera como complemento de la tarea etnográfica. Respecto del procesamiento interpretativo de los datos, se empleó como apoyo el software de análisis cualitativo Atlas.ti, en su versión 6.2.

Por último, cabe señalar que, al tratarse de un referente empírico multidimensional, tal como aquí es concebida, esta acción colectiva es susceptible de múltiples formas de ingreso al campo, para informar sobre la experiencia multivariada de explorar y habitar la Marcha (Roldán, Alonso \& Farías-Iten, 2016). En este sentido, resulta clave no solo el empleo de un conjunto de técnicas de construcción de datos, sino también el aporte de miradas teóricas y disciplinarias diversas que, en el equipo de investigación mencionado -que incluye a psicólogos/ as y politólogas- se materializa en las distintas trayectorias de formación de sus miembros y que, asimismo, echa mano de perspectivas antropológicas y sociológicas sobre la acción colectiva. La puesta en práctica de estas modalidades de triangulación de técnicas, teorías e interinvestigadores configura una suerte de "mosaiquismo metodológico" (Bonvillani, 2015) que colabora en el ejercicio de una actitud colectiva que permite aproximarse a estas experiencias de organización política desde una perspectiva atenta a lo múltiple y a lo complejo. Los productores y habitantes de esta acción colectiva generan sentidos y percepciones a partir de su propia experiencia de organizarse y marchar. De este modo, la Marcha no puede ser considerada como una superficie homogénea y definida de antemano 
(Bonvillani, 2018), sino que supone escenarios múltiples e, incluso, paradojales: el componente participativo y la relativa estabilidad témporo-espacial de la mesa organizativa se contrapone a la fugacidad y la movilidad propias del avance de la Marcha en el escenario de la calle. Esta mirada situacional y dialógica, atenta a la complejidad de la acción colectiva y a las múltiples formas de pertenencia de quienes la habitan, permite contemplar analíticamente los modos en que los sujetos participantes toman posición en el proceso de construcción política de la Marcha. En este sentido, el interrogante que recorre las reflexiones analíticas se vincula con el interés por indagar de qué modo los acuerdos y consensos construidos en el espacio organizativo de la Marcha se materializan en producciones colectivas y de carácter público, las que, en este caso, constituyen la imaginería propia de la acción colectiva. De este modo, el trabajo busca poner en tensión el registro de las discusiones y los procesos decisorios en el marco de la mesa organizativa con la producción de las gráficas oficiales en tanto producto de tales construcciones y negociaciones políticas.

\section{ANÁLISIS DE GRÁFICAS Y CONSIGNAS DE LAS DOCE EDICIONES DE LA MARCHA DE LA GORRA}

\section{$1^{\circ}$ edición (año 2007)}

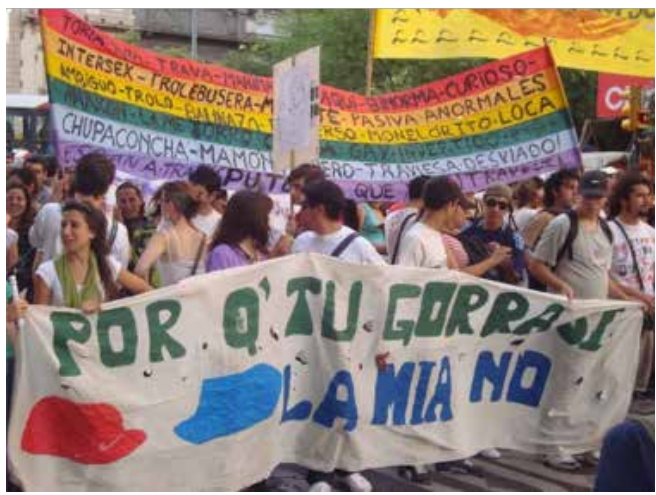

Figura 1. Fotografía correspondiente a la 1 Edición de la Marcha de la Gorra (año 2007).

La Primera Marcha de la Gorra da continuidad a una primera movilización que bregaba por los derechos de los niños y niñas. Precisamente, se fija el día 20 de noviembre como la fecha de realización de la Marcha, puesto que es reconocido por 
la Organización de las Naciones Unidas como el Día Internacional de los Derechos de los Niños, Niñas y Adolescentes.

Esta primera marcha no tuvo una gráfica oficial de difusión. La organización era aún incipiente y el proceso organizativo no presentaba el grado de sofisticación que tiene actualmente en su dinámica de trabajo por comisiones. La fotografía que se incluye en este apartado (Figura 1) constituye un documento histórico de la Marcha; es por esto que se optó por incluirla. Simultáneamente, contiene una consigna que luego aparecería insistentemente en sucesivas ediciones: ¿Por qué tu gorra sí y la mía no? Esta locución se vale del juego de palabras y de la cualidad multívoca del objetosímbolo gorra. La gorra constituye un elemento que, por asociación con atributos de peligrosidad y delincuencia como parte de un proceso de etiquetamiento social, se constituye en un accesorio de vestuario por el cual los jóvenes de sectores populares son señalados como sospechosos. Sin embargo, al mismo tiempo, "gorra" es una categoría local, con una fuerte carga peyorativa, que se emplea para designar a los agentes policiales o a la institución policial per se. Teniendo su origen en esta primera marcha, esta interpelación pasaría a tener estatus de consigna, de grafiti y de bandera en posteriores ediciones.

En sus primeras ediciones -hasta el año 2012, aproximadamente- la Marcha presenta matices propios de un repertorio de movilización muy colorido, un tanto carnavalesco, donde se postula de manera insistente la reivindicación de la cultura popular juvenil. Una cultura popular desacreditada e impugnada desde la mirada hegemónica (Bonvillani, 2015), que cobraba materialidad en las detenciones que se producían en la vía pública, particularmente en las calles del centro de la ciudad de Córdoba (Etchichury, 2007). De este modo, las posibilidades de libre acceso y libre circulación por las calles del centro de la ciudad, para los niños y jóvenes de sectores populares, se constituiría en la demanda primigenia de la Marcha de la Gorra.

\section{$2^{\circ}$ edición (año 2008)}

Cuando se toma la decisión de reiterar la Marcha de la Gorra en Córdoba, el Colectivo de Jóvenes por Nuestros Derechos comenzaba a consolidarse como un espacio que perduraría durantelos próximos diez años, y ya no con el único objetivo de organizar el evento-Marcha, sino con el propósito de organizarse de manera sostenida en contra del abuso policial (Roldán, 2016). Así, la primera gráfica de diseño, elaborada para convocar a la Marcha, ofrece también una La cuestión de las detenciones arbitrarias continúa operando como núcleo motivacional para organizarse y llevar adelante una acción de protesta. No obstante, emergen nuevas 

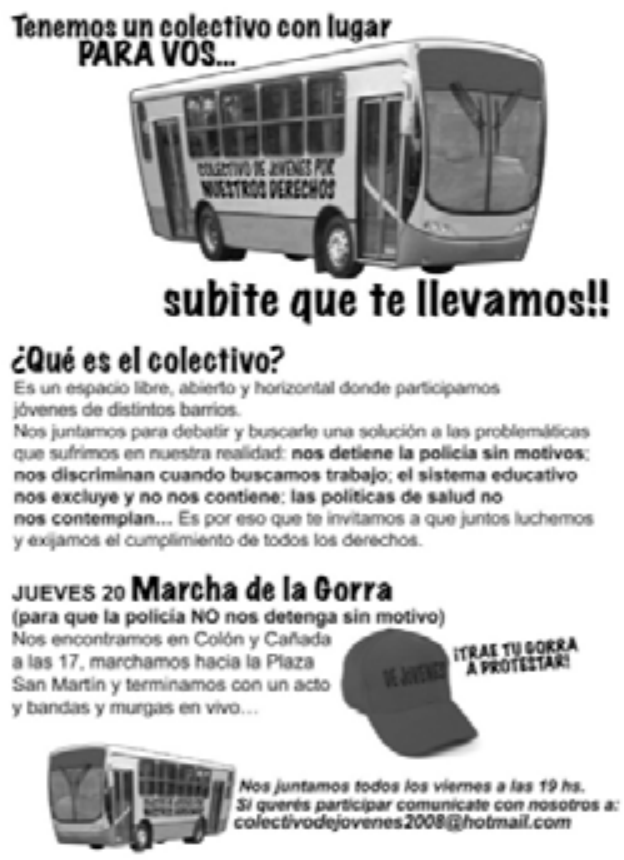

Figura 2. Gráfica correspondiente a la 2 Edición de la Marcha de la Gorra (año 2008)

construcciones de sentido que se refieren a la problemática de la discriminación, a las dificultades de acceso al mundo del trabajo, en buena medida obstaculizado por la sistematicidad que adquieren estas detenciones en la vía pública (Plaza \& Morales, 2013). En esta producción visual se hace mención también a las múltiples exclusiones en el sistema de salud y el sistema educativo. De este modo, puede observarse que, a partir de una expansión de las lecturas críticas sobre los complejos procesos de exclusión y desigualdad -que precarizan las vidas de los jóvenes de sectores populares-, pasa a componer el núcleo de demandas de la Marcha un conjunto de malestares que se refieren a procesos sociales más amplios y estructurales.

\section{$3^{\circ}$ edición (año 2009)}

Para el año 2009, la Marcha de la Gorra ya comenzaba a ganarse un lugar en la agenda política de diversos espacios partidarios, territoriales, estudiantiles y del tercer sector. 
La violencia ejercida por la institución policial comienza a ser presentada bajo la categoría "abuso", y la noción de seguridad aparece asociada al concepto de derechos. El elemento que más se destaca iconográficamente se refiere a la afirmación de "Los jóvenes al centro", tematizando, una vez más, las constantes dificultades de las y los jóvenes de los barrios periféricos para acceder al espacio céntrico de la ciudad.

En este punto, resulta pertinente realizar algunas puntualizaciones sobre las regulaciones en el espacio público cordobés, que no se limitan a un control selectivo de parte de las fuerzas policiales (Roldán, Alonso \& Farías-Iten, 2016) como se denuncia en la Marcha de la Gorra, sino que, además, se sostienen en toda una ingeniería de planificación urbana y en políticas habitacionales con trazos segregacionistas (Boito \& Michelazzo, 2014). Específicamente, se trata de la constitución de las denominadas ciudades-barrio, desde los primeros años de la década 2000. Estas se emplazan en los márgenes de la trama urbana cordobesa y

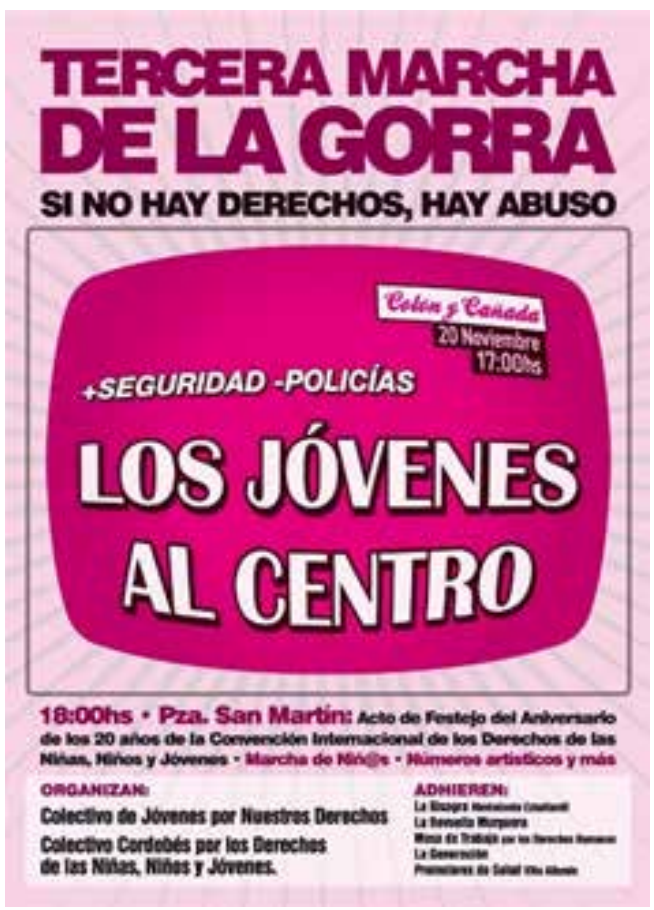

Figura 3. Gráfica correspondiente a la $3^{\circ}$ Edición de la Marcha de la Gorra (año 2009) 
se configuran como los nuevos espacios habitacionales de las familias de sectores populares que fueron desplazadas desde zonas más céntricas de la ciudad hacia la periferia.

En contextos de marcada desigualdad social, como es el caso de América Latina, los procesos de fragmentación se materializan en el espacio público y las ciudades se constituyen en zonas de disputa en las que las experiencias de circular/habitar aparecen fuertemente permeadas por los condicionamientos étnicos y de clase (Lindón, 2015). Es por esto que la cuestión del acceso al espacio público ocupa un lugar tan central en el núcleo de demandas que se configura en torno a la Marcha de la Gorra, y que puede observarse a lo largo de diferentes ediciones.

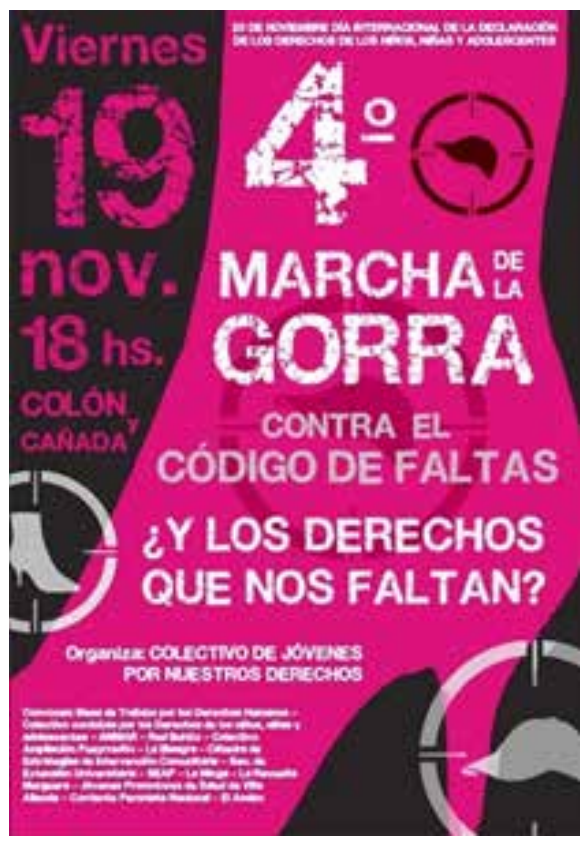

Figura 4. Gráfica correspondiente a la 4º Edición de la Marcha de la Gorra (año 2010)

\section{$4^{\circ}$ edición (año 2010)}

En esta $4^{\circ}$ edición de la Marcha aparece enunciado por primera vez y de manera explícita el reclamo contra el Código de Faltas, demanda que quedará 
históricamente asociada a la Marcha de la Gorra. Este Código, en tanto dispositivo que forma parte de las políticas públicas de seguridad de la provincia, puede entenderse en el marco de lo que se conoce como doctrina de la "tolerancia cero" (Wacquant, 2004). Entre otras construcciones de sentido, este tipo de concepciones parte de la premisa de que existiría una correspondencia entre el delito y ciertas conductas u acciones entendidas como "incivilidades", a saber, sujetos en situación de calle, personas con consumo problemático de sustancias e incluso el ejercicio del trabajo sexual, bajo el supuesto de que estos grupos atentarían contra cierto orden social hipervalorado. En este caso, las trabajadoras sexuales aparecen en escena de un modo particular, constituyéndose en sujetos protagónicos de esta acción colectiva, conquistando incluso un lugar preponderante en la gráfica de esta edición 2010. En esta imagen aparecen una serie de miras de tiro y, como objetivo, aparecen ya no solo la gorra, sino también "el taco" (calzado), figura que opera como símbolo del trabajo sexual. Las trabajadoras sexuales comenzaron a plantear que también ellas eran objeto de detenciones arbitrarias en razón de su práctica laboral, colaborando con una nueva ampliación de las demandas de la Marcha.

Con la pregunta ¿Y los derechos que nos faltan? parece producirse un juego de palabras con la pretensión de caricaturizar el nombre del Código -Código de Faltas-, denunciando la amenaza que representa para un conjunto de derechos fundamentales, producto de su aplicación abusiva.

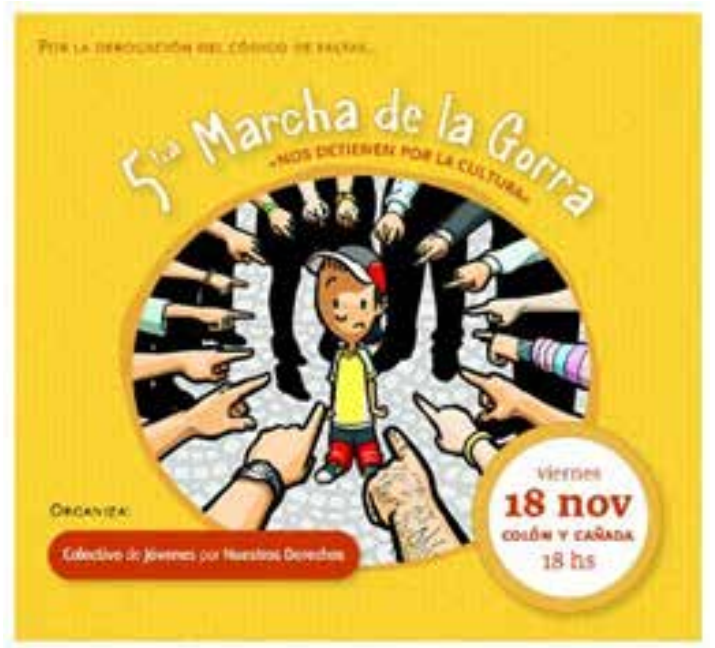

Figura 5. Gráfica correspondiente a la 5 Edición de la Marcha de la Gorra (año 2011) 


\section{$5^{\circ}$ edición (año 2011)}

En las gráficas de la $5^{\circ}$ edición se insiste con la exigencia de derogación del Código de Faltas; no obstante, aparece también la leyenda "Nos detienen por la cultura”. De acuerdo con algunos autores (Bonvillani, 2015; Crisafulli, 2013), el color oscuro de la piel constituye uno de los atributos físicos determinantes para que se produzcan las detenciones. Se trata de toda una serie de prejuicios y estigmatizaciones que se activan en lo que Crisafulli (2013) denomina el "olfato policial".

El emblema de este hostigamiento es caracterizado por los jóvenes con el nombre de "portación de rostro", como una forma de parodiar la arbitrariedad con que algunos sujetos se perfilan como contraventores y otros como simples transeúntes en el espacio público. Pero esta gráfica introduce, además, la novedad de postular que las detenciones se producen debido a que estos jóvenes se ubican con relación a determinadas adscripciones culturales -vinculadas fundamentalmente con la cultura popular-, las que, al ser concebidas como subvalores, son desacreditadas y evaluadas como peligrosas (Bonvillani, 2015). De este modo, la Marcha se presenta a manera de un espacio y un tiempo de denuncia, de protesta, de "revancha" $y$, fundamentalmente, de encuentros, de estar-con-otros, que reúne múltiples expresiones juveniles, artísticas y culturales que portan sentidos políticos que disputan y compiten con los poderes y discursos hegemónicos.

\section{$6^{\circ}$ edición (año 2012)}

La sexta edición de la Marcha de la Gorra estuvo signada por un suceso que, en cierto modo, marcó un momento bisagra en la lucha antirrepresiva en Córdoba. En febrero de 2012 desapareció Facundo Rivera Alegre, y su madre, Viviana Alegre, comenzó una lucha incansable por encontrar a los culpables de la desaparición de su hijo denunciando la responsabilidad de agentes policiales. Este hecho encendió una señal de alarma, pues ya no se trataba solo de detenciones arbitrarias en la vía pública, sino que se estaba ante la desaparición de un joven de 20 años que hasta hoy no ha sido encontrado.

En la gráfica correspondiente a esta edición, bajo la consigna "Tu código trata de desaparecer nuestra alegría callejera”, se introduce la cuestión de la desaparición en contraposición a la alegría de la calle, de lo popular y de lo juvenil. La alegría se constituye en una especie de derecho a ser reivindicado y, simultáneamente, en la experiencia y en la reflexión colectiva que moviliza la Marcha en su mesa organizativa es caracterizada como una herramienta de lucha, como una forma de resistencia. La alegría se proyecta a la manera de una expresión obscena e irónica: 
"una de-mostración polémica de estar en la calle, donde los cuerpos juveniles se mueven sin prevención y las voces de reclamo se levantan y se vuelven grito desafiante" (Bonvillani, 2013, p. 101).

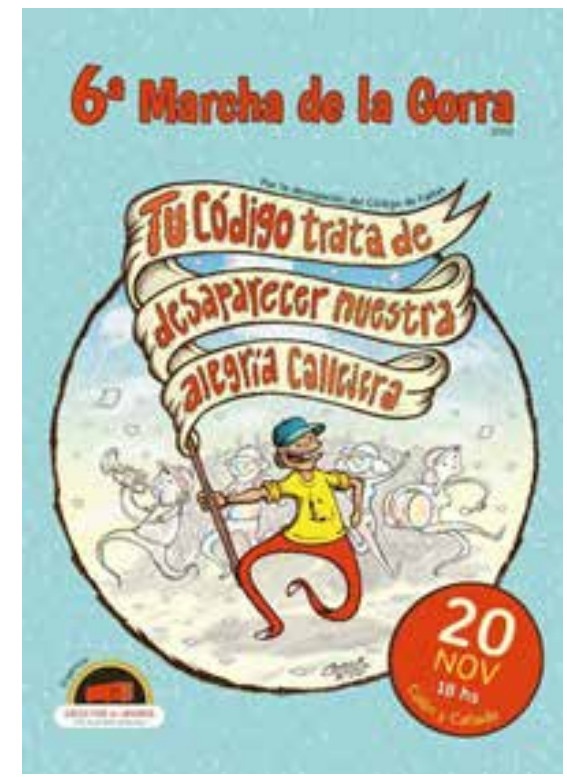

Figura 6. Gráfica correspondiente a la 6 Edición de la Marcha de la Gorra (año 2012)

\section{$7^{\circ}$ edición (año 2013)}

Hasta el año 2013, las demandas centrales que instala la Marcha tienen que ver fundamentalmente con las detenciones arbitrarias y las aplicaciones del Código de Faltas, como ya se ha explicado. A más de un año de la desaparición de Facundo Rivera Alegre, las percepciones y los sentires en torno a la verdadera incidencia de la Marcha en el escenario de represión en Córdoba comienzan a denotar un clima de mayor tensión.

"Tu seguridad nos limita, nuestra resistencia es infinita", versa la consigna bajo la cual se marchó en el año 2013. Las políticas públicas de seguridad continúan estando en el centro de las discusiones. La gráfica conserva el colorido de ediciones anteriores, incluyendo la figura del policía como objetivo hacia el cual se dirige el conjunto de gorras, con un paisaje urbano de fondo. Las adhesiones a la Marcha se incrementaron significativamente al momento de realizarse esta edición, tanto en lo que respecta al número de espacios políticos, partidarios, territoriales, 
estudiantiles y de ONG que brindaron su apoyo público a la Marcha, como en lo relativo a la convocatoria en la calle, que ha venido in crescendo año a año.

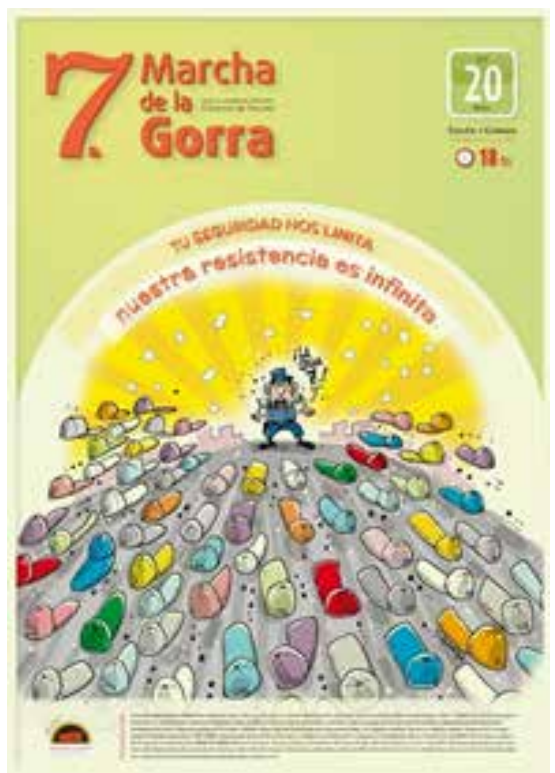

Figura 7. Gráfica correspondiente a la 7º Edición de la Marcha de la Gorra (año 2013)

\section{$8^{\circ}$ edición (año 2014)}

La mesa organizativa de la Marcha se convoca usualmente en septiembre de cada año. Hasta dicho mes, en 2014, se contabilizaban en la provincia siete casos de gatillo fácil ${ }^{2}$, es decir, un promedio de aproximadamente un caso por mes. El escenario sin duda se había recrudecido. Uno de los casos que más trascendencia mediática tuvo fue el de un joven conocido como "Güere” Pellico, quien murió víctima de un disparo por la espalda, ejecutado por un policía, mientras circulaba en su motocicleta.

La bronca y el descontento con estas condiciones contextuales impregnaron las discusiones de la mesa organizativa de la Marcha. Comenzaba a instalarse cada

\footnotetext{
${ }^{2}$ Categoría local "gatillo fácil": forma coloquial de aludir, en Argentina, a las causas de muertes producidas por un uso abusivo de armas de fuego y en las que se ven involucrados miembros de las fuerzas policiales.
} 
vez con más pregnancia la pregunta en torno a los efectos políticos y materiales de la Marcha, en un escenario en el que el abuso policial y la persecución a estos jóvenes, lejos de reducirse, parecía ir en aumento, engrosando los índices de jóvenes asesinados en circunstancias que involucraban a la institución policial.

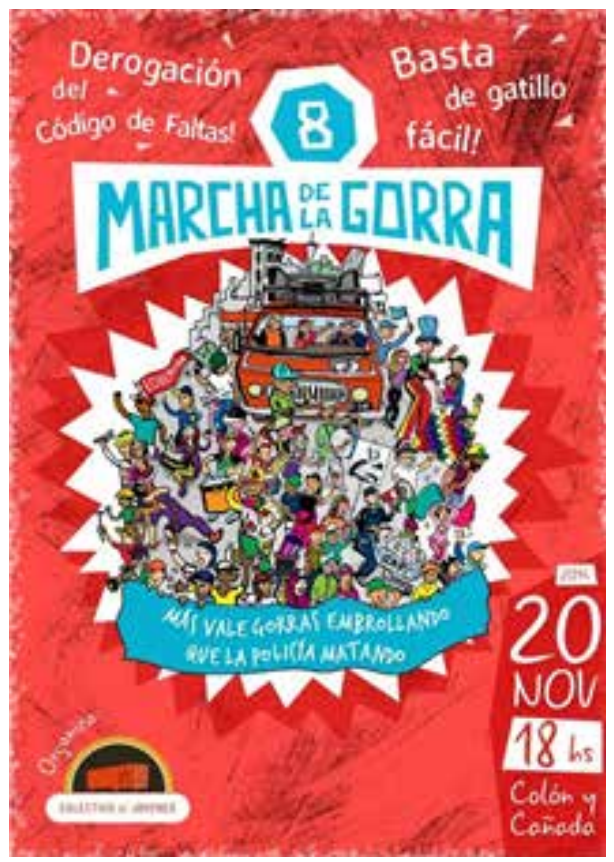

Figura 8. Gráfica correspondiente a la $8^{\circ}$ Edición de la Marcha de la Gorra (año 2014)

En la gráfica predomina el color rojo como elemento intrusivo. El rojo es un color vinculado tradicionalmente con los partidos de izquierda en el plano político y, coloquialmente, también asociado con la sangre (Rivera, 2001). Por primera vez, se enuncia en las gráficas y en la consigna, de manera abierta, la problemática del "gatillo fácil", del homicidio impune de jóvenes, lo que actualmente algunos autores latinoamericanos conceptualizan en términos de juvenicidio (Valenzuela, 2015). Se aborda en esta consigna, de manera directa, la problemática del asesinato, y se señala a la institución policial como responsable directa de esas muertes. No obstante, la gráfica conserva algo del componente más bien lúdico o festivo que se reivindicaba en ediciones anteriores de la mano de la cultura popular. Este tipo de expresiones se 
condensan en la inclusión de la categoría local embrollar. El significado del embrollo fue ampliamente debatido y "rellenado" de sentido en la instancia de discusión de la mesa organizativa correspondiente a esta edición. El verbo embrollar aparece asociado con "meterse en líos", "provocar caos", a la vez que presenta un sentido de picardía, de travesura. Se recupera, además, como en muchas otras gráficas, el objeto-símbolo gorra, asociado con la estética de los jóvenes de los barrios. De este modo, se reivindica la cultura popular de estos jóvenes "embrollando" en el centro de la ciudad, a la vez que se cuestiona y se sanciona el accionar asesino de la policía. Esta quizás sea la gráfica que exhibe con mayor claridad la convivencia de los diversos climas emocionales (De Rivera, 1992) en que navega la Marcha de la Gorra (Roldán, 2016).

\section{$9^{\circ}$ edición (año 2015)}

Aparece el sintagma "Estado policial" en la consigna oficial ${ }^{3}$. Por primera vez, el Estado es señalado como el antagonista principal con el cual la Marcha disputa sentidos y poder. A su vez, aparece adjetivizado en su rol punitivo, de control, de persecución y de administración de la fuerza y la violencia: "policial". La presencia del Estado, para estos jóvenes, aparece materializada a modo de hostigamiento y persecución, incluso de muerte.

Tras un año de un lamentable incremento de los casos de gatillo fácil, en 2015 tiene lugar un gran operativo que consistió en la efectivización de razias policiales en diferentes barrios populares de la ciudad, dejando un alto saldo de allanamientos, muy cuestionados en cuanto a su legalidad y detenciones injustificadas (Ardiles, Castro \& Rebollo, 2015). De esta forma, por primera vez, el Estado alcanza un papel protagónico en el diseño de las gráficas oficiales de la Marcha, en tanto antagonista principal al que procura interpelar la acción colectiva.

Sin embargo, una vez más, aún se conservan imágenes e íconos que remiten a la presencia de intervenciones artísticas en la Marcha, como es el caso de las murgas, los instrumentos musicales y los colores, entre otros elementos que remiten a la idea de celebración y de carnaval. El color verde que predomina en esta gráfica quizás no produce el mismo impacto del color rojo de la edición 2014. Esto último es discutido y señalado en la reunión de evaluación correspondiente a esta Marcha, por parte de actores protagónicos de la mesa organizativa, como una debilidad o un

\footnotetext{
${ }^{3}$ Consigna: "En tu Estado policial, te marchamos de frente mar". La expresión "de frente mar" constituye una categoría local que hace referencia a una certeza, convicción o afirmación que no ofrece lugar a dudas.
} 

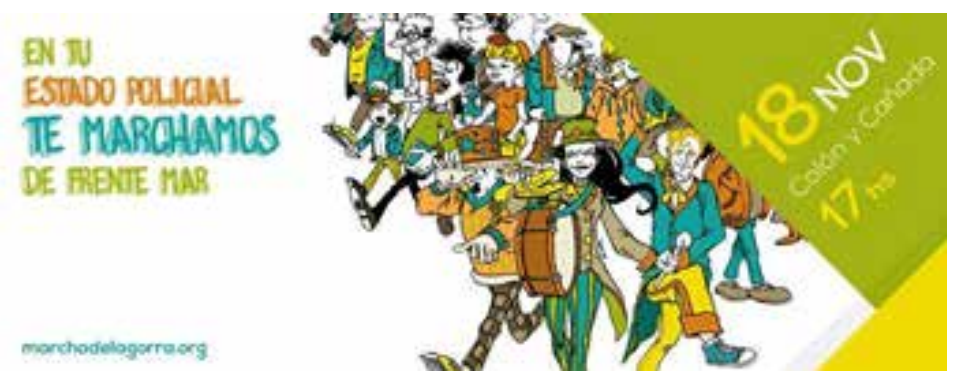

Figura 9. Gráfica correspondiente a la 9² Edición de la Marcha de la Gorra (año 2015)

"retroceso" en la imaginería de la protesta, a la vez que se destaca como un acierto la identificación del Estado como el antagonista clave al que "se le hace" la Marcha.

\section{$10^{\circ}$ edición (año 2016)}

Un dato clave respecto de esta edición se vincula con el hecho de que, a fines de 2015, tuvo lugar la sanción del nuevo Código de Convivencia Ciudadano, en reemplazo del cuestionado Código de Faltas. Desde la mesa organizativa de la Marcha de la Gorra se sostuvo que la sustitución de un código por otro no significaría ninguna transformación en materia antirrepresiva y que no representaba

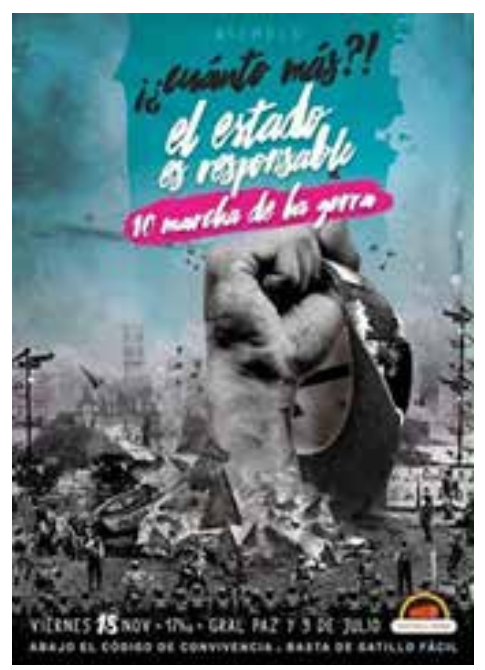

Figura 10. Gráfica correspondiente a la 10² Edición de la Marcha de la Gorra (año 2016) 
una modificación real de la situación de desigualdad e injusticia en relación con los jóvenes de sectores populares y sus posibilidades de usufructuar el espacio público. Este nuevo código entró en vigencia en abril de 2016 y su repudio se materializó en la gráfica de esta edición, a la vez que se insistió en sostener la denuncia y el rechazo radical a los casos de gatillo fácil, acompañado de la expresión "BASTA", que ya había sido introducida en afiches anteriores.

Se trata de una gráfica muy particular, puesto que presenta cierta continuidad con la edición anterior en tanto que conserva la figura del Estado como el antagonista principal, el cual ahora es señalado como el responsable directo de las violencias que la acción colectiva denuncia. Sin embargo, esta imagen introduce una clara ruptura en relación con los elementos más bien joviales o festivos de la Marcha destacados otrora. Ya no afloran banderines, murgas, instrumentos o colores animados. En esta ocasión, sobre una gama de azules como trasfondo, lo que emerge es una mano en forma de puño cerrado, sosteniendo con vigor una gorra, que irrumpe bruscamente desmembrando el paisaje urbano, de extenso asfalto, ocupado por un cordón de policías. El puño apretado puede ser pensado como símbolo de bronca contenida y, a su vez, transmite la idea de una fuerza concentrada que irrumpe en la escena.

La pregunta "i¿cuánto más?" se vincula con los sentimientos de hartazgo y de bronca acumulada frente a la violencia estatal y policial que, lejos de retroceder, ha exhibido facetas más cruentas en los últimos años. A su vez, a instancias de discusión de la consigna de esta edición, una de las jóvenes de la mesa organizativa plantea que el grito de cuánto más le recuerda la consigna Nunca más, emblemática en la recordación y el repudio de la última dictadura militar argentina. Es interesante apreciar los modos en que la construcción de sentidos de una acción colectiva actual parece reeditar y entrar en diálogo con sentidos y emociones asociados con luchas predecesoras, que se inscriben en la memoria colectiva de los sectores combativos. Cuánto más... si continúan las muertes, las desapariciones, los asesinatos, el abuso de poder de parte de las fuerzas del Estado. “¿Cuánto más debemos soportar de la violencia de Estado?”, parece ser el interrogante fundamental de esta nueva edición de la Marcha, de acuerdo con lo expresado en su gráfica y su consigna.

\section{$11^{\circ}$ edición (año 2017)}

En esta producción iconográfica de la Marcha, una vez más, ya no hay espacio para la inclusión de la "alegría callejera" o para reivindicar la cultura popular como una dimensión destacada de la lucha. El Estado, nuevamente, es ubicado en el centro de la escena como el antagonista principal de esta acción colectiva. Es presentado como agencia de muerte que dirige sus mecanismos punitivos y de persecución a grupos 
específicos de la sociedad: "El Estado nos mata", "Nuestra lucha avanza". En esta consigna opera una diferenciación, un distanciamiento respecto de la figura del Estado. El Estado es el enemigo y la lucha parece ser incompatible con los canales organizativos institucionales tradicionales. A suvez, en esta edición, aparece como novedad una figura que hasta el momento no había sido considerada o enunciada de manera explícita en las consignas de marchas anteriores: los medios masivos (hegemónicos, podría agregarse) de comunicación. Estos medios son presentados como sostenedores, legitimadores y promotores de las políticas públicas de seguridad que se repudian, cuyo énfasis persecutorio tiene como blanco preferencial a los sectores populares. Finalmente, en el marco de los debates de la baja de la imputabilidad penal que comenzaron en 2017 en Argentina, la Marcha construye una nueva demanda en orden a desestimar y repudiar tales intenciones políticas, de corte marcadamente punitivo. A su vez, se mantiene la consigna "Abajo el Código de Convivencia" que ya había sido incluida el año anterior. Sin embargo, esta última leyenda aparece disminuida en relación con la de "Basta de gatillo fácil", problemática que, posiblemente por su gravedad, logró relegar del centro de la escena a las discusiones atinentes a las cuestiones legislativas, como es el caso de los códigos contravencionales.

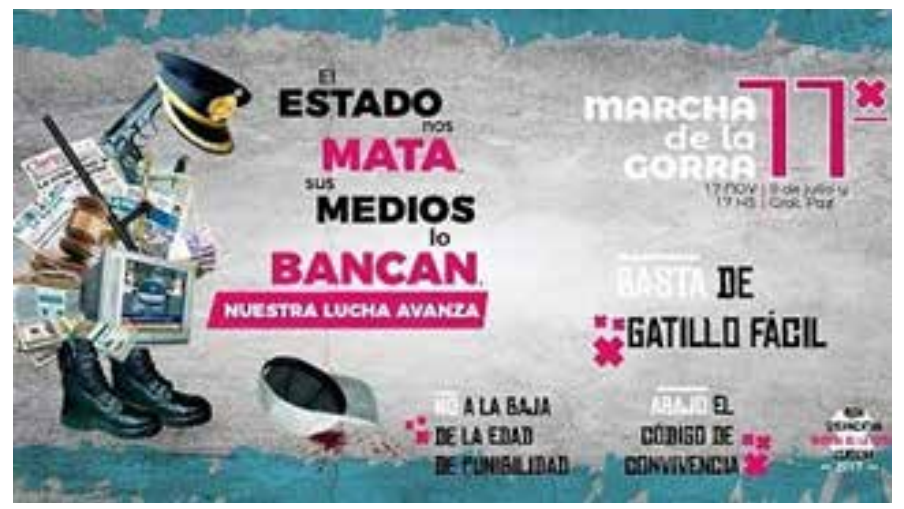

Figura 11. Gráfica correspondiente a la 11ºdición de la Marcha de la Gorra (año 2017)

\section{$12^{\circ}$ edición (año 2018)}

La $12^{\circ}$ constituye la última edición de la Marcha de la Gorra, hasta el momento en que se escribieron estas líneas. 2018 significó un año convulsionado en materia de organización antirrepresiva, dado que los efectos de la desaparición -y posterior aparición sin vida- de Santiago Maldonado, caso que generó enorme polémica y que involucraba a las fuerzas de Gendarmería Nacional, aún se dejaban notar en las 
agendas políticas y mediáticas a nivel nacional. A esto se agrega el controvertido suceso conocido como caso Chocobar, en que un policía disparó a un joven de 18 años, quien resultó muerto, en un hecho que las organizaciones sociales y de derechos humanos consideraron una ejecución extrajudicial (Fava, 2018). A posteriori de este hecho, tanto el Presidente de la Nación, Mauricio Macri, como la Ministra de Seguridad, Patricia Bullrich, se encontraron públicamente con el agente en cuestión, exhibiendo palabras de reconocimiento e incluso de exaltación respecto del comportamiento de este miembro de la fuerza, dando lugar a lo que mediáticamente se conoce como "doctrina Chocobar", haciendo alusión al respaldo brindado por parte del gobierno y a lo que las organizaciones antirrepresivas señalan como una forma de legitimación del "gatillo fácil" como política de seguridad. Este clima de álgida preocupación por el avance represivo, tanto en el plano de la criminalización de la pobreza, como de la protesta (Medan, 2017) -y su correspondiente legitimación de parte de miembros del Ejecutivo nacional- impregnó los debates de la mesa organizativa de la Marcha. En un escenario social, político y securitario caracterizado, en el marco de estas discusiones, como propulsor de sentimientos de desconfianza y temor para con otros miembros del cuerpo social, se insiste en postular al Estado como el máximo agente de miedo y terror en lo que respecta a la violación de garantías y derechos fundamentales. En este contexto, surge la expresión "terrorista es el Estado, no quien tenés al lado" como consigna que coronaría la $12^{\circ}$ edición de esta acción colectiva antirrepresiva que consolida su proyección nacional en el año 2018, replicándose en once ciudades del país.

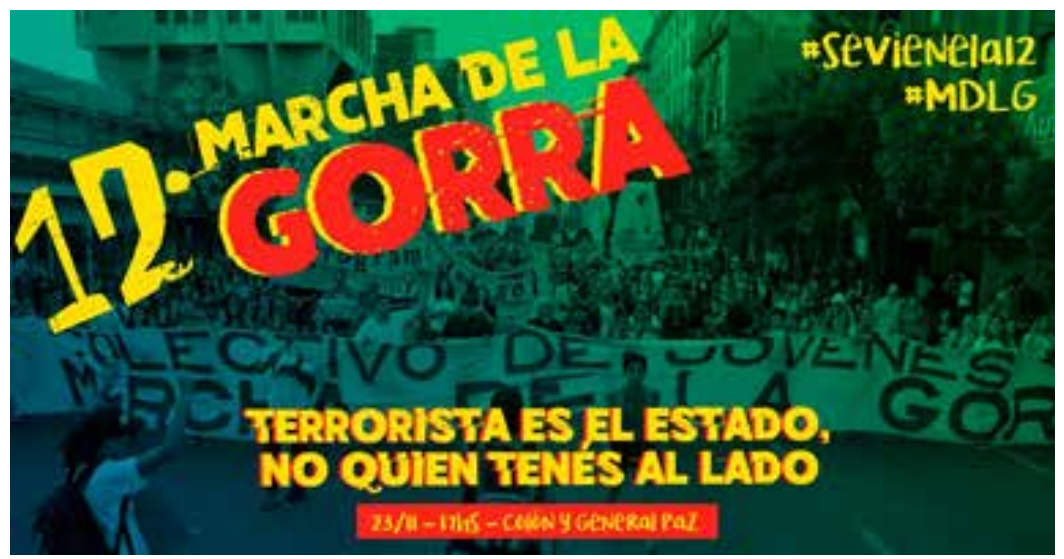

Figura 11. Gráfica correspondiente a la 11ºdición de la Marcha de la Gorra (año 2017) 


\section{DISCUSIÓN}

A partir del análisis de las gráficas y consignas oficiales correspondientes a cada una de las ediciones de la Marcha de la Gorra en Córdoba, es posible puntualizar algunos sentidos o conjeturas que insisten en relación con el proceso de construcción de esta acción colectiva.

Para comenzar, es importante atender al hecho de que la Marcha puede ser pensada, al menos, en dos momentos-espacios: la mesa organizativa, que se reúne desde el mes de septiembre, cada año, y la Marcha en sí, que tiene lugar una tarde específica en el mes de noviembre. Este último espacio, el de la calle, el de la realización efectiva de la protesta, consiste en una enorme columna de personas, entre 15.000 y 20.000 marchantes, de acuerdo con cada edición, que se convocan en el corazón del centro de la ciudad para marchar por una serie de demandas que se vinculan con la relación conflictiva entre jóvenes de sectores populares, políticas de seguridad e institución policial. Por otra parte, el momento que le antecede $-\mathrm{y}$ que lo posibilita- consiste en un espacio organizativo sostenido por un número mucho más pequeño de personas, aproximadamente entre 40 y 60 representantes de las distintas organizaciones que convocan, adhieren y apoyan la Marcha de la Gorra. Es claro que el nivel de complejidad en los debates y discusiones que habilita el encuentro sostenido, semana tras semana, presenta ciertos contrapuntos respecto de la fugacidad y la intensidad que supone la experiencia de estar marchando. En este sentido, la mesa organizativa opera como una especie de "cocina de la acción colectiva” en la que esta se amasa, se prefigura y se configura, al calor de los intensos procesos de discusión, negociación y co-construcción de sentidos entre los diferentes actores que la integran. Es preciso recordar que cada consigna y cada gráfica que se oficializa como parte de la producción iconográfica y discursiva de la marcha representa una acumulación de horas de intensos debates, de confrontación de diversos posicionamientos ideológicos e incluso de discusiones político-conceptuales. En este punto, es importante advertir la confluencia cada vez más frecuente y numerosa de estudiantes universitarios y académicos en la mesa organizativa, cuya participación complejiza los procesos decisorios en el plano del debate teórico-conceptual.

Un elemento clave que emerge del análisis es, sin duda, el lugar que el Estado ha ocupado en la concepción y en la enunciación de demandas de esta acción colectiva a lo largo de su historia. En las primeras ediciones es tomado como un interlocutor más al que se pretendía interpelar, del mismo modo que se aspiraba a hacerlo con la sociedad en general. Posteriormente, adquiere cierta posición de 
antagonista político al que se le realiza efectivamente el reclamo y se le demanda revertir la situación. Finalmente, en las últimas ediciones, se lo ubica claramente como el máximo responsable de lo que se concibe en tanto "crímenes de Estado", tal como son designados los casos de gatillo fácil y de desaparición de personas.

Por otra parte, una dimensión que no puede desestimarse en la construcción de las demandas que la Marcha propone cada año remite al lugar preponderante que ocupan las emociones en el activismo político y en la definición de un programa colectivo de acción. El aumento de los casos de gatillo fácil y de jóvenes asesinados por agentes policiales, el alto grado de intervencionismo en los barrios, como es el caso de las razias que tuvieron lugar en 2015, constituyen algunos de los elementos que contribuyeron a obnubilar aquellas banderas sobre la alegría callejera y de la fiesta popular que se enarbolaban propiamente en las primeras ediciones de la Marcha, cediendo lugar a climas emocionales (De Rivera, 199) vinculados con la pérdida, el hartazgo y el dolor ante lo irreparable. Estos elementos coyunturales se inscriben en el marco de un recrudecimiento de las políticas de seguridad, con un marcado aumento en el presupuesto público de la provincia destinado a reforzar la doctrina de tolerancia cero (Plaza \& Morales, 2013) que se ponen a tono con un Estado penal (Wacquant, 2004), insistiendo en una suerte de paternalismo punitivo que hace foco en la población juvenil de sectores populares.

Por último, es necesario atender al hecho de que los acuerdos y consensos que se construyen en la mesa organizativa, siempre producto de intensos debates y en un escenario donde se tensionan procedencias políticas e ideológicas diversas, como ya ha sido señalado, acaban luego viéndose confrontados con lo que efectivamente ocurre el día de la Marcha. Teniendo en cuenta la masiva convocatoria que esta acción colectiva presenta, puede comprenderse que aquella Marcha que idean y procuran construir los y las organizadores/as opera, muchas veces, como un marco general organizativo, siempre sujeto a la inmanencia y a la espontaneidad de la puesta en acto de dicha movilización. Por otra parte, en la Marcha parece mantenerse cierta convivencia de climas emocionales que navegan entre las pasiones tristes y las pasiones alegres, que dotan de cierta multiplicidad a la experiencia afectivizada de la Marcha, aunque no siempre esta diversidad de matices se vea reflejada en las demandas que se exhiben en la consigna y la gráfica consensuada por la organización.

Finalmente, puede ser enriquecedor ofrecer algunos comentarios respecto de la dimensión metodológica de este estudio, que se enmarca a su vez en una trayectoria de investigación de más de seis años en torno a la Marcha de la Gorra. La complejidad que supone la exploración de acciones colectivas, en sus múltiples aspectos afectivos, simbólicos, cognitivos, organizacionales, de la práctica, etc., requiere de 
metodologías flexibles en su diseño e implementación y abiertas a perspectivas múltiples. En esta línea de trabajo, se hizo mención al empleo de un mosaiquismo metodológico (Bonvillani, 2015) que acompaña las sucesivas aproximaciones al campo, nutriéndose de aportes teórico-conceptuales y metodológicos que tienen su origen en distintas disciplinas de las ciencias sociales y que se apoya en una pluralidad de técnicas que, en el caso de este proceso de investigación ha contemplado: la etnografía de evento, como estrategia general de exploración de la Marcha; observación participante; registro etnográfico; análisis de documentos; entrevistas en profundidad; entrevistas abiertas grupales; conversaciones-enmarcha, técnica delineada por el equipo de investigación; etnografía virtual; historias de vida y producción de registros fotográficos y fílmicos, dando lugar a un nutrido corpus etnográfico. En la línea de estudio desarrollada en este artículo, se trabajó con los insumos empíricos provenientes del registro etnográfico, la observación participante y el examen de documentos (en este caso, imágenes, correspondientes a las gráficas oficiales de la Marcha), para producir un análisis diacrónico de las demandas que se han ido configurando al calor de la organización de esta acción colectiva. De acuerdo con Martínez y Cubides (2012), este tipo de procesos de investigación tienen un carácter singular, que los ubica en el paradigma cualitativo y navegan entre enfoques interpretativo-hermenéuticos y crítico-sociales. Por otra parte, la intención de estudiar las problemáticas sociales como procesos resulta determinante $y$, en este sentido, sostener un enfoque cualitativo permite abordar los objetos de estudio desde una perspectiva holística, evitando reducir los escenarios y los grupos a variables aisladas.

\section{CONSIDERACIONES FINALES}

A partir del análisis de las gráficas y consignas oficiales de cada edición de la Marcha de la Gorra, así como de los procesos de producción de estas, se llevó a cabo un análisis diacrónico de sus demandas, contemplando los debates que emergen al interior de la mesa organizativa, las transformaciones coyunturales y la progresión de múltiples nudos de discusión y elaboración política. Como se vio, el empleo de metodologías cualitativas flexibles y abiertas a la construcción de datos en torno a los aspectos afectivos, simbólicos, cognitivos y prácticos de la acción colectiva, resulta determinante en los procesos de investigación orientados por una perspectiva de lo múltiple y lo complejo, que abordan experiencias de organización política y de resistencia en contextos de opresión.

Atender los complejos procesos de construcción de consensos y de enunciación 
de demandas al interior de un movimiento, en este caso, una Marcha con más de una década de historia, supone abordar la acción colectiva como una compleja producción mancomunada que comienza en las múltiples negociaciones y disputas políticas entre los diferentes sujetos, grupos y organizaciones que trabajan en su concepción. Aquellas que constituyen producciones consensuadas de la acción colectiva -en este caso en análisis, las consignas y las gráficas oficiales de la Marchaque, en un primer acercamiento podrían ser pensadas como elementos simples, espontáneos o como una especie de eslogan político, abrigan en su materialidad, de hecho, todo un proceso de construcción y de significación que se gesta y se elabora de manera colectiva.

En este sentido, el contexto sociopolítico, el impacto de la acción colectiva en experiencias anteriores y la posibilidad de constatar efectos en relación con la problemática en cuestión, constituyen procesos clave en la construcción, el desplazamiento y la reconfiguración de las demandas en la acción colectiva.

\section{BIBLIOGRAFÍA}

Ardiles, B.; Castro, J. \& Rebollo, S. (2015). Conflictividad segura. XI Jornadas de Sociología. Facultad de Ciencias Sociales, Universidad de Buenos Aires, Argentina.

Belting, H. (2007). Antropología de la imagen. Madrid: Katz. Madrid.

Boito, M. E. \& Michelazzo, C. (2014) Córdoba en pedazos. Habitar/circular en contextos sociosegregados. Estudios sociales contemporáneos, (10), 45-58.

Bonvillani, A. (2013). Cuerpos en marcha: emocionalidad política en las formas festivas de protesta juvenil. Revista Nómadas, (39), 91-103.

Bonvillani, A. (2014). Saberes apasionados horizontes de construcción de conocimiento de las subjetividade(s) política(s). En Piedrahita Echandía C., Díaz Gómez A. \& Vommaro P. (Comps.) Acercamientos metodológicos a la subjetivación política: debates latinoamericanos. Clacso. Colombia: Magisterio.

Bonvillani, A. (2015). Callejeando la alegría... y también el bajón. Etnografía colectiva de la Marcha de la Gorra. Córdoba, Argentina: Encuentro Grupo Editor.

Bonvillani, A. (2018). Etnografía colectiva de eventos: la cronotopía paradojal de la Marcha de la Gorra (Córdoba, Argentina). De prácticas y discursos, 7(9), 161-184.

Bonvillani, A. \& Roldán, M. (2017). Politización de los cuerpos juveniles: la Marcha de la Gorra como performance multitudinaria. Aposta. Revista de Ciencias Sociales, (74), 165-203.

Borges, A. (2004). Tempo de Brasília: etnografando lugares-eventos da política. Río de Janeiro: Relume Dumará.

Cisafulli, L. (2013). Neo racismo latinoamericano, la seguridad como excusa y el paradigma de los Derechos Humanos. Apertura, 1, (1).

De Rivera, J. (1992). Emotional climate: Social structure and emotional dynamics. International Review of Studies on Emotion, (2), 197-218. 
Etchichury, H. (2007). Preso sin abogado, sentencia sin juez. El CDF de la Provincia de Córdoba. En I Congreso Argentino-Latinoamericano de Derechos Humanos: una mirada desde la universidad, Rosario, Argentina: Subsecretaría de Cultura de la Universidad Nacional de Rosario, Argentina.

Fava, N. (2018). El discurso securitario del gobierno argentino. "Doctrina Chocobar" y tácticas discursivas anti derechos y garantías. Bordes. Revista de política, derecho y sociedad. Agostooctubre de 2018.

Guber, R. (2004). El salvaje metropolitano. Reconstrucción del conocimiento social en el trabajo de campo. Buenos Aires: Paidós.

Lindón, A. (2015). Del espacio público de las hexis corporales al de las afectividades brumosas y no discursivas. Revista Latinoamericana de Estudios sobre Cuerpos, Emociones y Sociedad, (17), 8-19.

Martínez, M. C. \& Cubides, J. (2012). Acercamientos al uso de la categoría de 'subjetividad política' en procesos investigativos. En Piedrahita Echandía C., Díaz Gómez A. \& Vommaro P. (Comps.) Subjetividades políticas: desafíos y debates latinoamericanos. Colombia: Magisterio.

Medan, M. (2017). ¿Prevención social del delito como criminalización de la pobreza? Una apuesta a considerar las interacciones cotidianas entre operadores institucionales y beneficiarios/as. Papeles de Trabajo, 11 (19), 77-98.

Plaza, V. \& Morales, S. (2013). Seguridad y democracia: Tensiones de origen. Aportes al análisis de la política de seguridad en la provincia de Córdoba. Estudios, (29), 111-131.

Rivera, M. E. (2001). Percepción y significado del color en diferentes grupos sociales. Imaggen. Revista de la Universidad Simón Bolívar, (53), 74-83.

Roldán, M. (2016). La "Marcha de la Gorra": indagando acerca de las implicancias de la emocionalidad política en procesos de subjetivación política con juventud(es) cordobesas. Tesis de grado no publicada. Facultad de Psicología, Universidad Nacional de Córdoba, Argentina.

Roldán, M.; Alonso, M. R. \& Farías-Iten, D. P. (2016). Procesos de subjetivación política en la acción colectiva juvenil. Revista Jangwa Pana, 15(2), 165-180.

Tarrow, S. (1997). El poder en movimiento. Los movimientos sociales, la acción colectiva y la política. Madrid: Alianza.

Valenzuela, J. M. (2015). Juvenicidio. Ayotzinapa y las vidas precarias en América Latina y España. Barcelona: Ned. El Colegio de la Frontera Norte.

Wacquant, L. (2004). Las cárceles de la miseria. Buenos Aires: Manantial. 